\title{
ABO Blood Groups and Cardiovascular Diseases
}

\author{
Hanrui Zhang, ${ }^{1,2}$ Ciarán J. Mooney, ${ }^{1,2}$ and Muredach P. Reilly ${ }^{1,2}$ \\ ${ }^{1}$ Cardiovascular Institute, Perelman School of Medicine, University of Pennsylvania, Philadelphia, PA 19104-6160, USA \\ ${ }^{2}$ Institute for Translational Medicine and Therapeutics, University of Pennsylvania School of Medicine, Philadelphia, \\ PA 19104-5158, USA \\ Correspondence should be addressed to Muredach P. Reilly, muredach@mail.med.upenn.edu
}

Received 20 June 2012; Revised 25 August 2012; Accepted 1 September 2012

Academic Editor: Masaki Mogi

Copyright (๑) 2012 Hanrui Zhang et al. This is an open access article distributed under the Creative Commons Attribution License, which permits unrestricted use, distribution, and reproduction in any medium, provided the original work is properly cited.

\begin{abstract}
ABO blood groups have been associated with various disease phenotypes, particularly cardiovascular diseases. Cardiovascular diseases are the most common causes of death in developed countries and their prevalence rate is rapidly growing in developing countries. There have been substantial historical associations between non-O blood group status and an increase in some cardiovascular disorders. Recent GWASs have identified ABO as a locus for thrombosis, myocardial infarction, and multiple cardiovascular risk biomarkers, refocusing attention on mechanisms and potential for clinical advances. As we highlight in this paper, more recent work is beginning to probe the molecular basis of the disease associations observed in these observational studies. Advances in our understanding of the physiologic importance of various endothelial and platelet-derived circulating glycoproteins are elucidating the mechanisms through which the ABO blood group may determine overall cardiovascular disease risk. The role of blood group antigens in the pathogenesis of various cardiovascular disorders remains a fascinating subject with potential to lead to novel therapeutics and prognostics and to reduce the global burden of cardiovascular diseases.
\end{abstract}

\section{Introduction}

In 1901, Landsteiner identified ABO blood groups as the first recognized human blood group system. The clinical significance of $\mathrm{ABO}$ blood type extends beyond transfusion medicine and solid organ/hematopoietic transplantation. To date, numerous reports have suggested important associations between $\mathrm{ABO}$ blood groups and various diseases, for example, gastric cancer [1], periodontal diseases [2], and cardiometabolic diseases $[3,4]$.

According to World Health Organization (WHO) data, cardiovascular diseases (CVDs) are and will remain the leading causes of death globally: an estimated 17.3 million people died from CVD in 2008, representing 30\% of all global deaths (WHO Media Centre (2011), cardiovascular diseases (fact sheet). retrieved from http://www.who.int/ mediacentre/factsheets/fs317/en/index.html). Studies on the associations between $\mathrm{CVD}$ and $\mathrm{ABO}$ blood groups have a long history. In 1955, Woolf proposed an odds ratio as a measure to quantify the disease risk conferred by blood group type [5]. In 1969, Jick et al. reported a deficit of patients with blood group $\mathrm{O}$ among those who received anticoagulants for venous thromboembolism [6]. Prior to mutation detection in haemophilia carriership analysis, likelihood ratios of carriership of hemophilia A were based on Factor VIII levels conditional on blood group [7]. A number of later studies elucidated that $\mathrm{ABO}$ blood groups, particularly non-O blood groups, are associated with major cardiovascular risk factors and/or increased rate of cardiovascular events [8-13]. However, there is limited consensus regarding the magnitude and significance of the ABO effects at the population level, and whether it relates to all disorders equally or predominantly modulates thrombotic pathways and disorders [14]. This paper summarizes the basic concepts of the biochemistry of $\mathrm{ABO}$ blood groups and recent findings of their relations to CVD. 


\section{Biochemistry and Population Distribution of ABO Blood Groups}

The ABO blood group is determined by the presence of $\mathrm{A}$ and $B$ antigens on the surface of the red blood cells (RBCs). In addition to RBCs, these antigens are widely expressed on the membranes of a wide variety of cells, including platelets, vascular endothelium and epithelium [15] as well as in saliva and body fluids [16]. The biochemistry of the ABO blood group system has been reviewed recently [16]. Briefly, the $\mathrm{ABH}$ blood group antigens consist of terminal carbohydrate molecules which are synthesized by the sequential action of the $\mathrm{ABO}$ glycosyltransferases. The $A B O$ glycotransferase (transferase A, alpha 1,3-N-acetylgalactosaminyltransferase; transferase B, alpha 1,3-galactosyltransferase) gene encodes proteins related to the $\mathrm{ABO}$ blood group system $[17,18]$. The active $\mathrm{ABO}$ glycotransferases catalyze the addition of specific monosaccharides to a common core precursor antigen $(\mathrm{H})$ to form distinct $\mathrm{A}$ and $\mathrm{B}$ antigens. Individuals with blood group $\mathrm{O}$ express only the basic $\mathrm{H}$ antigen [19] due to a deletion of guanine-258 in the region of the gene encoding the $\mathrm{N}$ terminus of the protein which results in a frameshift and translation of a protein lacking glycosyltransferase activity $[17,18]$.

The frequency of the common $\mathrm{ABO}$ phenotypes varies among different populations. Populations with a high frequency of the A phenotype are found mainly in Northern and Central Europe [18]. The B phenotype is most frequent in Central Asia [18]. Blood group O is the most frequent phenotype globally, with parts of Africa and Australia showing highest frequencies [18]. The reasons for the observed differences among populations are not well understood, although several theories have been proposed. Evolutionary selection based on pathogen-driven blood group antigen changes may be one of the major contributors [18]. Under this theory, terminal carbohydrate modification on host proteins, lipids, and cells plays a significant role in modulating interactions with pathogens. Thus, ambient pathogens are thought to have driven the regional evolution and selection of host blood group antigens that provide survival advantage to distinct geographic pathogen exposures.

\section{Genome-Wide Association Studies Confirmed ABO as a Locus for Venous Thromboembolism and Myocardial Infarction}

The widespread use of genome-wide association studies (GWASs) over the last 5 years has spurred an enormous acceleration in discoveries across the entire spectrum of CVD [20]. Recent GWASs have confirmed $A B O$ as a locus for venous thromboembolism (VTE), myocardial infarction (MI), and multiple cardiovascular biomarkers (Table 1).

One of the most studied aspects of the $A B O$ gene is its relationship with von Willebrand factor (VWF) [17, 36, 37]. In 2003, a family-based linkage screen was carried out to determine the loci involved in VWF variation in 398 Spanish individuals. Markers at the chromosome 9q
$A B O$ locus region harbored the highest LOD value of 3.46 [38]. Subsequently, several GWASs have shown that carriers of single nucleotide polymorphisms (SNPs) that mark non-O blood group types have higher levels of plasma VWF when compared to $\mathrm{O}$ individuals. A recent GWAS of 7856 European participants in the Atherosclerosis Risk In Communities (ARIC) cohort study showed that $\mathrm{ABO}$ blood group $\mathrm{O}$ carriers had a $25 \%$ average reduction in plasma VWF levels when compared with non-O blood group carriers. SNP rs514659, which was used to tag the O blood type, contributed to $15.4 \%$ of circulating VWF variance [33]. Additionally, a genome-wide meta-analysis of 4 cohorts found that rs657152, which also tags the blood group $\mathrm{O}$, was strongly associated with circulating VWF levels and that blood group $\mathrm{O}$ individuals had 22-30\% lower plasma VWF when compared to non-blood group $\mathrm{O}$ individuals [28]. A relationship between Factor VIII (FVIII) plasma concentrations and $\mathrm{ABO}$ blood groups has also been seen. However, in a Cohorts for Heart and Aging Research in Genome Epidemiology (CHARGE) Consortium GWAS, no unique genetic variants within the $\mathrm{ABO}$ locus were found to affect FVIII independently of VWF [34]. As VWF binds and transports FVIII, the correlation between the $\mathrm{ABO}$ gene and FVIII is most likely mediated via VWF [39].

As increased plasma levels of VWF and Factor VIII are associated with greater risk of thrombosis [40, 41], many studies have examined the connection between ABO blood group and thrombotic risk. In a GWAS published in 2009, SNPs rs8176750, rs8176746 and rs8176719, which tag the $\mathrm{A} 2, \mathrm{~B}$, and $\mathrm{O} \mathrm{ABO}$ blood groups, respectively, showed that genetically inferred blood type $\mathrm{O}$ had $67 \%$ lower risk of VTE than non-O blood groups. Additionally, the A2 blood group had $47 \%$ lower risk of VTE when compared to the other non-O blood group phenotypes [32]. Blood type A2 was also shown to be associated with lower VTE risk in a recently published GWAS involving 1,503 VTE patients in which rs8176704 was used to tag the A2 blood group [23]. These data suggest that the decreased risk of VTE is a result of reduced $\mathrm{H}$ antigen glycosylation, as the A2 allele contains a 1061delC that results in the synthesis of an enzyme that has 30-50 fold less A transferase activity than the A1 allele product [42]. Blood group genotypes may be more informative than blood group phenotypes in studying the association between blood groups and VTE since genotypes can distinguish between heterozygous and homozygous carriers of $\mathrm{A}, \mathrm{B}$, and $\mathrm{O}$ alleles and between A1 and A2 alleles $[43,44]$. One GWAS found that the A11 allele, tagged by rs529565 and rs657152, and the B allele, tagged by rs 8176749 , were associated with $56 \%$ and $16 \%$ increased risk of VTE, respectively, when compared to the O11 allele. Moreover, when compared with carriers of the O1O1 diplotype, VTE risk was increased by $79 \%$ for the A11 diplotype, $82 \%$ for the $\mathrm{B}$ diplotype, and $170 \%$ for the $\mathrm{AB}$ diplotype carriers. Overall, non-O categories combined were associated with a 77\% increased risk of VTE when compared to the $\mathrm{O}$ category [29]. The effect of $\mathrm{ABO}$ genotype on thrombosis risk was also investigated in a case-control study of 471 patients and 471 controls of the Leiden Thrombophilia Study (LETS) which revealed that non-OO genotypes, except 


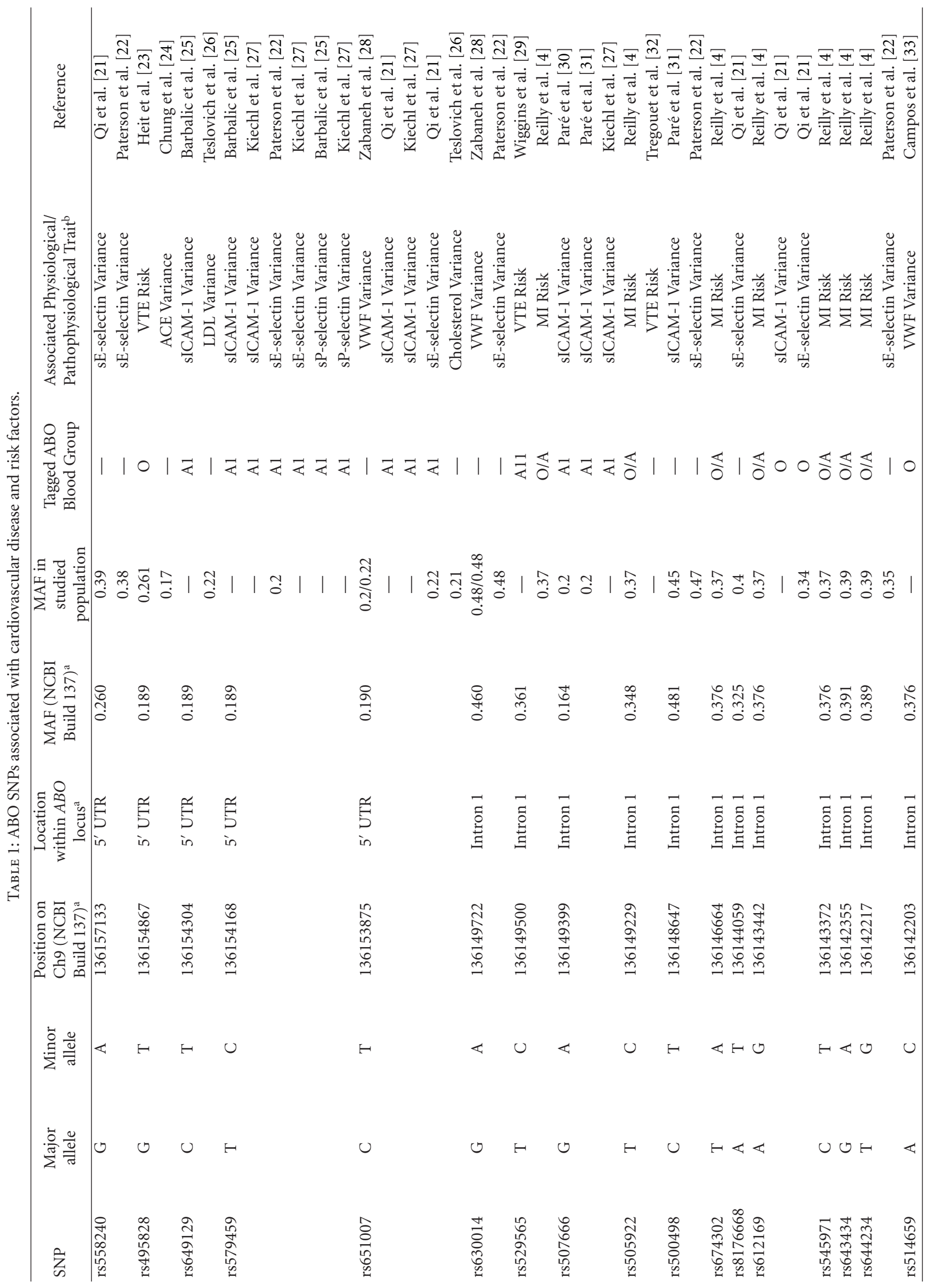




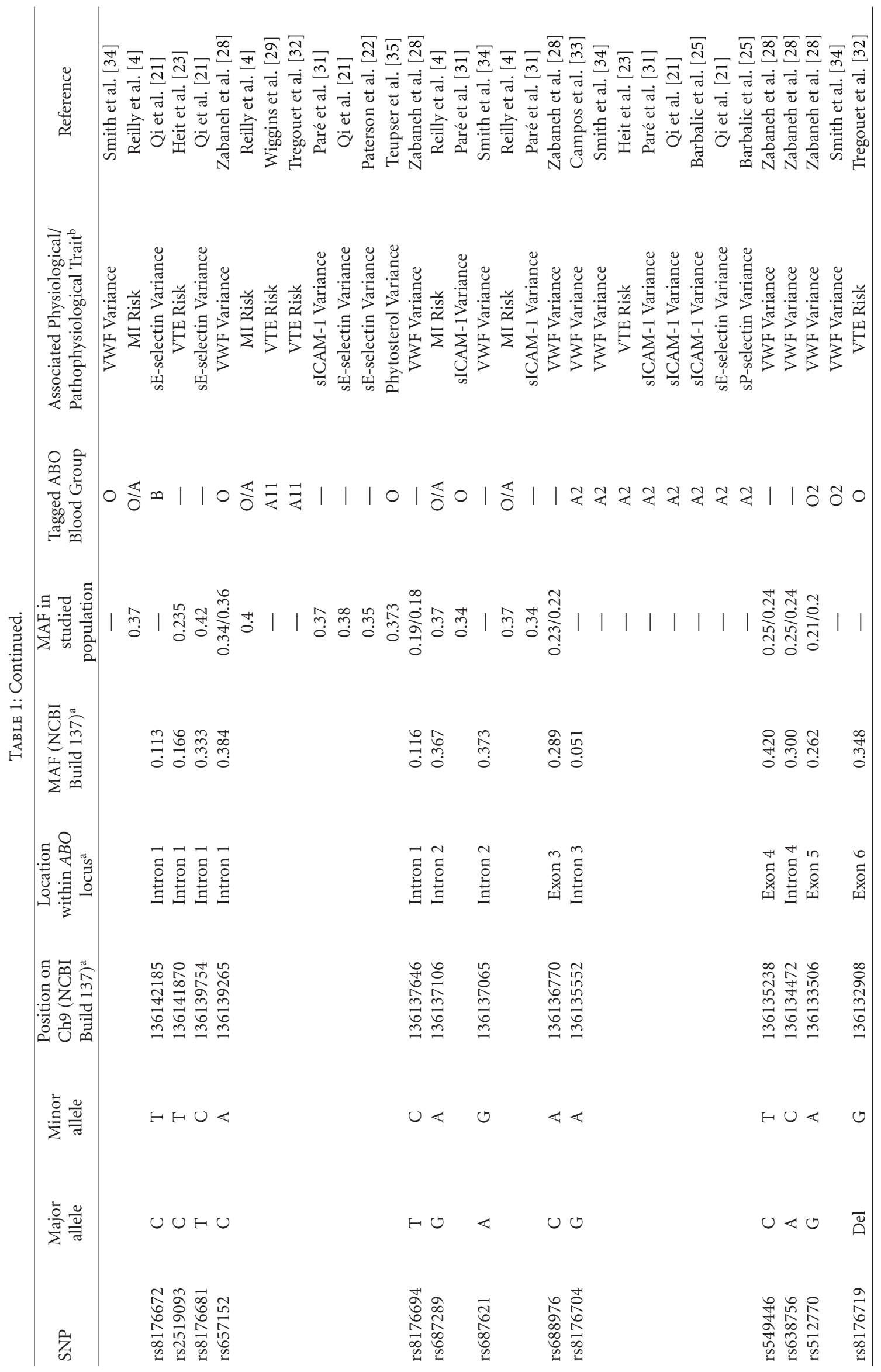




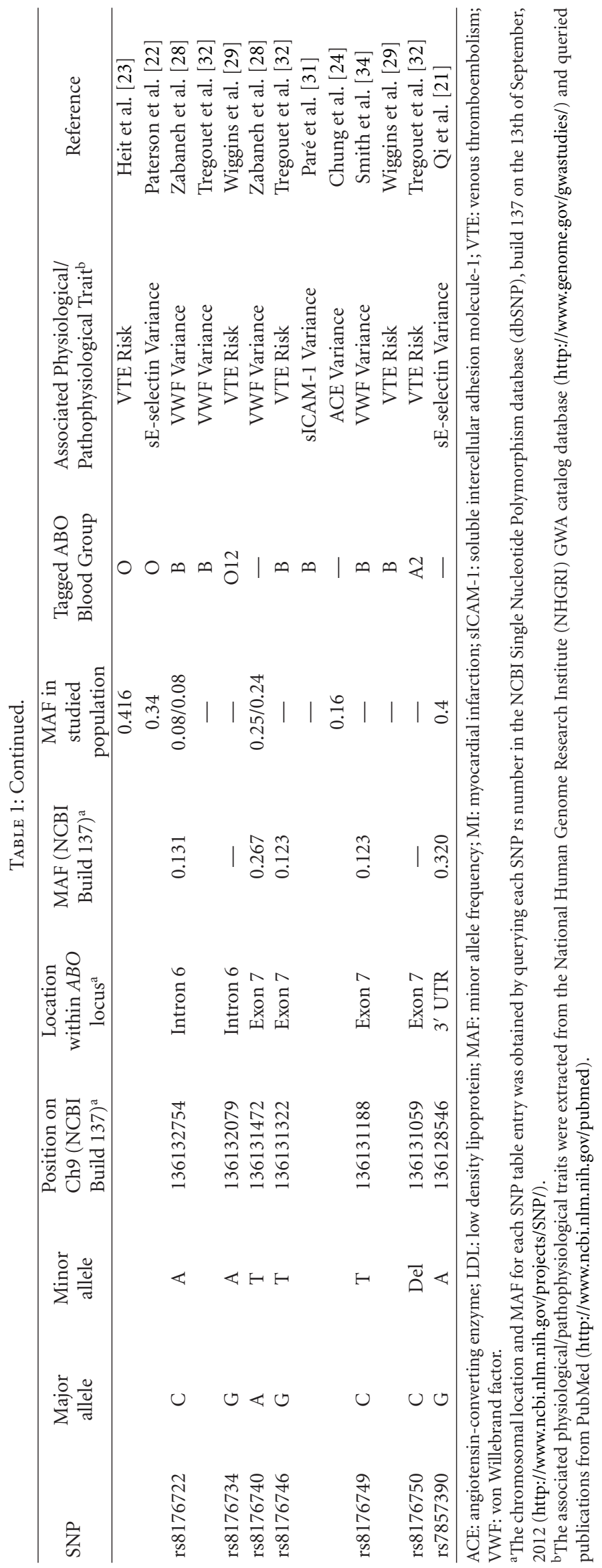


homozygous A2 and A2-O combinations, were associated with increased thrombotic risk when compared to $\mathrm{OO}$ genotypes. The relative thrombotic risk of $\mathrm{AB}$ genotypes and A1-combinations was increased by $90-110 \%$ when compared to $\mathrm{OO}$ genotypes and the relative thrombotic risk of the homozygous $\mathrm{B}$ genotype and $\mathrm{B}-\mathrm{O}$ combinations was increased by $60 \%$ [45].

The ABO locus has also been associated with arterial thrombosis in studies of MI. Our group reported that all 11 SNPs that exceeded genome-wide significance for MI in patients with established coronary atherosclerosis mapped to the ABO locus. The risk alleles at rs514659 (odds ratio 1.21; $P=7.62 \times 10^{-9}$ ) and rs687289 (odds ratio $1.19 ; P=7.75 \times$ $10^{-9}$ ) were perfect tags for the loss of function $\mathrm{ABO} O$ blood group demonstrating that functional $\mathrm{ABO}$ glycotransferases conferred increased risk of MI. Further analysis found that rs514659 was associated with coronary artery diseases (CADs) when complicated by MI but not with CAD without MI, suggesting that the primary relationship of $A B O$ to clinical CAD is through modulation of coronary thrombosis or plaque rupture in patients with established coronary atherosclerosis rather than through primary promotion of atherosclerosis per se.

The increase in MI risk for non-O blood type individuals has been suggested for some time through epidemiological studies, although there has been debate as to which $\mathrm{ABO}$ blood group phenotypes confer the largest increase in risk $[8,11,46-49]$. Just recently, He et al. reported results of two large prospective studies of incident coronary heart disease (CHD) as well as a meta-analysis of all prospective data [50]. The Nurses' Health Study (including 62,073 women ages 30 to 55 at baseline) and the Health Professionals Followup Study (including 27,428 men ages 40 to 75 at baseline) were followed up to 2006 and recorded 2,055 cases of CHD in the two cohorts. Individuals with self-reported non-O blood type had an age-adjusted hazard ratio (HR) of 1.09 (95\% CI 1.03 to $1.17, P=0.005$ ) for risk of developing CHD. Associations between blood type and CHD risk were not modified by age, physical activity, alcohol consumption, smoking status, or diabetes history. A meta-analysis of an additional six prior cohorts, for a combined total of 114,648 individuals and 5,741 CHD cases, also showed a significant pooled relative risk for CHD in patients with non-O blood type of 1.11 ( $95 \%$ CI 1.05 to $1.18, P=0.001$ ). Among participants in the cohort, those with type O blood were significantly less likely to develop CHD when compared against types $\mathrm{B}$ (HR 1.11, 95\% CI 1.01 to 1.23 ) and $\mathrm{AB}$ (HR $1.23,95 \% \mathrm{CI} 1.10$ to 1.37 ), with a trend toward a higher risk for patients with type A blood (HR 1.05, 95\% CI 0.98 to 1.13).

It is plausible that $\mathrm{ABO}$ modulation of VWF-related thrombosis accounts for the $\mathrm{ABO}$ association with MI. However, $\mathrm{ABO}$ antigens are expressed also on distinct platelet proteins, including GPIIb, a subunit of the fibrinogen receptor heterodimer [51-54], and may therefore modulate specific platelet functions in arterial thrombosis and MI (see below). In addition, ABO modulation of atherosclerotic plaque rupture and atherosclerosis itself cannot be discounted without further study.

\section{Associations of the $\mathrm{ABO}$ Locus with Markers of Endothelial Function and Serum Lipoproteins}

The $\mathrm{ABO}$ glycotransferase may have broader impact on atherosclerotic CVD than simply through modulation of thrombosis. A series of GWAS have linked the ABO locus to circulating levels of soluble intercellular adhesion molecule1 (sICAM-1), soluble P-selectin (sP-selectin), and soluble Eselectin (sE-selectin). Notably, mechanistic studies in rodent models have implicated these proteins in atherosclerosis [5559] and their blood levels in humans correlate with increased risk of CVD events $[60,61]$. Paré et al. showed that SNP rs507666, located in Intron 1 of the $A B O$ gene and a perfect tag for $\mathrm{ABO}$ blood group $\mathrm{A} 1$, was associated with decreased levels of sICAM-1 $\left(P=5.1 \times 10^{-29}\right)$ when compared to the $\mathrm{O}$ allele and contributed to $1.5 \%$ of the total sICAM1 concentration variance [31]. The same group confirmed this relationship between rs507666 and circulating sICAM-1 levels in a larger GWAS published in 2011 [30]. Blood levels of sP-selectin and sE-selectin are also associated with SNPs in the $\mathrm{ABO}$ region $[21,22,25]$. A recent meta-analysis showed that, compared with major allele homozygotes, heterozygote and minor allele homozygote individuals for the rs507666, rs579459, and rs651007 SNPs, which demonstrate a high degree of linkage disequilibrium with each other $\left(r^{2} \sim 0.96\right)$ and tag the $\mathrm{ABO} \mathrm{Al}$ subtype, had lower plasma levels of sICAM-1, sP-selectin, and sE-selectin [27]. A recent GWAS has also identified a potential relationship between $A B O$ and circulating levels of angiotensin-converting enzyme (ACE); when compared to the $\mathrm{ABO}$ blood group $\mathrm{O}$, mean ACE activity in carriers of blood group B was significantly increased $\left(P=2.3 \times 10^{-10}\right)$ while ACE activity in blood group A was decreased $\left(P=1.5 \times 10^{-8}\right)$ [24].

Past epidemiological studies, some dating as far back as 50 years ago, have suggested evidence for $\mathrm{ABO}$ association with circulating levels of cholesterol, with non-O groups appearing to have higher levels [47, 62-65]. For example, in 1976 , Garrison et al. published an epidemiological analysis in the Framingham Heart Study showing consistent elevations of serum cholesterol levels in non-O blood groups when compared to the O blood group [47]. Some recent GWASs and their meta-analyses support this potential role for $\mathrm{ABO}$ genotypes in modulating circulating levels of total and LDL cholesterol, as well as phytosterols, established causal risk factors for atherosclerotic heart diseases $[26,35$, 66]. A meta-analysis of 46 lipid based GWAS reported an association between $A B O$ SNPs and serum cholesterol levels. Total cholesterol was increased by $2.3 \mathrm{mg} / \mathrm{dL}$ in heterozygote individuals for the $A B O$ rs651007 SNP when compared to major allele homozygotes $\left(P=8.66 \times 10^{-21}\right)$, while LDL cholesterol was increased by $2.05 \mathrm{mg} / \mathrm{dL}$ in heterozygote individuals for the $A B O$ rs649129 SNP when compared to major allele homozygotes $\left(P=7.85 \times 10^{-22}\right)$ [26]. A GWAS published in 2010 found that the ABO locus showed genome-wide-significance for association with phytosterol levels. Specifically, rs657152, which tightly tags the O1 allele, was found to be associated with decreased levels of 
circulating phytosterols. In a separate analysis, the study reported that individuals with the $\mathrm{O}$ allele had decreased campesterol concentrations when compared to the A and $B$ alleles. Furthermore, additional analyses revealed that rs657152 was associated with reduced CAD risk $(P=$ $4.0 \times 10^{-5}$ ) when compared to alleles that were associated with increased phytosterols [35]. These epidemiological and genetic associations of $\mathrm{ABO}$ blood type with levels of circulating lipoproteins and sterols underscore the need for functional studies that define the mechanistic basis of these relationships and the potential for therapeutic translation.

Overall, these pleiotropic associations with cardiovascular risk biomarkers suggest a complex role of $\mathrm{ABO}$ in atherosclerotic and vascular diseases with distinct $\mathrm{ABO}$ genotypes and $\mathrm{ABO}$ functions contributing to multiple causal pathways, for example, $\mathrm{ABO}$ genotypes related to blood group $\mathrm{O}$ and loss of glycotransferase function protect against VTE and MI while distinct genotypes relating to specific A and B blood subgroups and glycotransferase functions may have a more subtle and distinct impact on endothelial function, lipoproteins, and atherosclerosis (Table 1).

One paradox that has limited clinical interpretation of GWAS discoveries, including that for the $A B O$ locus, relates to the highly significant $P$ values reported for common disease variants despite very small effect sizes (e.g., odds ratio). Unlike rare disease causing mutations, common variants for complex diseases have either minor functional effects or are simply crude markers for rare functional variants; their strength of association with disease is often very small despite highly significant $P$ values (which relate mostly to the sample size of GWAS). However, the weak effect sizes of these variants should not be mistaken for a lack of clinical importance of a particular gene (or protein/biomarker) or its therapeutic manipulation in a complex disease process. For example, rare variants in 3-hydroxy-3-methyl-glutarylCoA (HMG-CoA) reductase have quite weak associations with LDL cholesterol (LDL-C) levels and are well down the list of top GWAS findings for LDL-C [26]. Thus, rather than attempting to infer clinical relevance based on the strength of associations, the key importance of GWAS is simply to identify novel genes and proteins for human disease that warrant further study to establish their mechanistic role and clinical importance. Over time, the totality of evidence derived from human, animal, and functional studies allows an interpretation of the clinical and therapeutic importance of the initial significance level for a locus in a GWAS, the magnitude of effect on a protein level, and the relative risk of a given protein level for a disease phenotype. For the $A B O$ locus, further mechanistic and functional studies are required in order to define the clinical and therapeutic possibilities.

\section{Potential Mechanisms for the Association between ABO and CVD}

Following recent GWAS discoveries, there is a resurgent interest in identifying the mechanistic links underlying the association of the $\mathrm{ABO}$ locus and glycotransferase functions with CVD. Most attention until recently was focused on the role of $\mathrm{ABO}$ in regulating VWF bioactivity and related thrombotic pathways, but emerging work is defining more broadly the role of $\mathrm{ABO}$ glycotransferase activity in modulating multiple endothelial, platelet, and cardiometabolic pathways and exploring whether these effects are causally involved in cardiometabolic diseases.

5.1. VWF and FVIII as Candidate Mechanisms. VWF and FVIII are glycoproteins (GPs) that circulate together in normal plasma as a noncovalent complex and both play important roles in normal hemostasis. VWF is a carrier for FVIII and protects it from inactivation. VWF recruits platelets to the site of clot formation during primary hemostasis. Factor VIII is released from VWF by the action of thrombin and participates in the coagulation cascade. Thus, both VWF and FVIII are key proteins in the formation of occlusive thrombi in injured vessels [67]. As described in preceding sections, relative to non-group $\mathrm{O}$, carriers of $\mathrm{ABO}$ blood group $\mathrm{O}$ have significantly lower circulating plasma VWF and FVIII levels [68]. Although this clinically important effect of ABO group on plasma VWF-FVIII levels is well established, the mechanism through which it is mediated is not completely resolved. $\mathrm{ABO}$ appears to have direct functional effects on circulating VWF and indirectly (via influence of VWF levels) modulates FVIII levels. The presence of abundant $\mathrm{ABH}$ carbohydrate molecules on the VWF oligosaccharide side chains provides the mechanistic basis for $\mathrm{ABO}$ regulation of VWF levels. The active $\mathrm{ABO} A$ and $B$ glycotransferase enzymes, found in Golgi of endothelial cells, generate terminal carbohydrate modifications, A and $\mathrm{B}$ antigens, on the existing VWF " $\mathrm{H}$ " oligisacharides, whereas the enzymatically inactive $\mathrm{ABO} O \mathrm{O}$ protein cannot modify these VWF $\mathrm{H}$ antigens. The addition of $\mathrm{A}$ or $\mathrm{B}$ terminal carbohydrate antigens to VWF in endothelial cells might influence circulating VWF levels and function by several mechanisms: altering the rate of VWF synthesis and/or secretion, regulating VWF proteolysis induced by its major protease, ADAMTS13, modulating VWF clearance, or changing VWF biological activity: or perhaps some combination of these events [17]. A number of studies suggest that it is unlikely that $\mathrm{ABO}$ effects on VWF levels are mediated by alterations in the biosynthesis and secretion of VWF [17]. In contrast, it has been demonstrated that the activity of ADAMTS13 differs against VWF of different blood groups, with both the level of ADAMTS13 activity [69], and the rate of VWF proteolysis by ADAMTS13 [70], being higher in blood group $\mathrm{O}$ as compared to non-O individuals. Thus, the absence of VWF terminal carbohydrate modifications in individuals with $\mathrm{ABO}$ blood group $\mathrm{O}$ increases the susceptibility to and rate of proteolysis by ADAMTS13, although data available so far are not in support of the role of proteolysis by ADAMTS13 in VWF clearance from the circulation [71]. Due to their physical association in blood, lower circulating VWF results in lower levels of FVIII. Whether VWF in platelets (a relatively abundant source) undergoes any modification by $\mathrm{ABO}$ remains controversial; such modification could alter platelet 
production and subsequent turnover of VWF, particularly locally during platelet-driven arterial thrombosis, although this remains to be established. Indeed, current knowledge suggests that $\mathrm{ABO}$ does not modify platelet VWF [72], but the role of $\mathrm{ABO}$ in regulating platelet $\mathrm{VWF}$ and platelet function in thrombosis requires greater study (see below).

\subsection{Other Endothelial Molecules and Platelet Proteins as} Potential Mediators. Soluble levels of multiple adhesion molecules, mostly derived from endothelial cells and platelets, have been associated with coronary heart disease [61], and other cardiovascular conditions [73]. In largescale genomic studies, plasma levels of sP-selectin and sICAM-1 were associated with $\mathrm{ABO}$ gene variants, but no association was found between platelet-bound P-selectin levels and $\mathrm{ABO}$ blood group, suggesting that the $\mathrm{ABO}$ blood group may influence proteolysis and clearance from the circulation, rather than its production and cellular presentation [25]. However, the specific mechanisms of $\mathrm{ABO}$ regulation of circulating levels of these endothelial GPs are largely unknown. Further, the implications for their function in atherosclerosis and clinical CVD require elucidation.

Blood group $\mathrm{ABO}$ antigens are known to be carried by several platelet GPs, for example, GPIb, GPIIb, GPIIIa, and platelet endothelial cell adhesion molecule (PECAM) [53], that play important roles in platelet function. Platelet $\mathrm{ABH}$ expression is a stable, donor-specific characteristic with $5 \%$ of $\mathrm{A} 1$ donors typing as either $\mathrm{ABH}$ high- or lowexpressers [74], with high levels of A antigen on various GPs from high-expresser platelets, especially GPIIb and PECAM (CD31) [51]. GPIIb is an integral component of the GPIIb-GPIIIa fibrinogen receptor complex, which represents the critical final common pathway for plateletdriven thrombosis in hemostasis and pathologic arterial thrombosis including acute MI. Genetic variation in GPIIb that modulates fibrinogen binding has been associated with altered risk of thrombosis and MI [75-77], so it is conceivable that $\mathrm{ABO}$-driven carbohydrate modification of GPIIb might alter its functional interactions with fibrinogen and thus platelet-mediated thrombosis. However, this hypothesis has not been adequately addressed to date. Besides GPIIb and PECAM, blood group A antigen is also expressed on other uncharacterized platelet proteins (70$90 \mathrm{kDa}$ ) having electrophoretic mobilities closely resembling those of GPIV and GPV [52]. Thus these and other uncharacterized $\mathrm{ABO}$-expressing platelet proteins may also act as potential functional modulators of the $A B O$ associations with arterial thrombosis and cardiovascular events.

The list of GPs carrying blood type $\mathrm{ABO}$ antigens is growing. Some of the most abundantly expressed GPs, such as PECAM and VWF, represent major proteins recognized to carry $A B O$ antigens. However, there is a great need to identify all $\mathrm{ABO}$ target proteins and glycolipids in order to understand the nature and/or properties of GPs carrying $\mathrm{ABO}$ antigens and to reveal novel, potentially cell-specific, mediators of CVD.

\section{Perspectives}

Despite the relative simplicity of the A and B antigens, especially considering the modest biochemical difference between them, the ABO blood group system appears to be one of the most interesting, both clinically and scientifically. It divides the world's population into four major groups. The common frequency of each major blood group, especially blood group $\mathrm{O}$ (the loss of glycotransferase function $\mathrm{ABO}$ type), suggests important evolutionary selection pressures distinct from heart disease which now have subtle but significant impact at the population level on complex diseases in modern society. Much larger epidemiological and genetic studies are required to determine risks of CVD with particular major and minor $\mathrm{ABO}$ blood group. Such human data will inform translational and mechanistic studies by pointing to specific $\mathrm{ABO}$ glycan modifications that appear to be the drivers of increased or decreased risk. However, such studies are inherently limited because they fail to illuminate the specific cell/tissue where glycan modifications are mediating their actions and do not define the proteins or lipids carrying such modifications that are functionally altered and mediate disease.

In future studies, it is of critical importance to establish clear mechanistic basis for the association between $\mathrm{ABO}$ blood groups and CVD. Advances in our understanding of the physiologic importance of the glycan structures of VWF have provided a model and elucidated one mechanism, possibly the major one, through which $\mathrm{ABO}$ blood group determines risk of thrombosis and acute cardiovascular events. However, there are several other known endothelial and platelet GPs, discussed above, that are potentially functionally modified by $\mathrm{ABO}$ and candidate causal mediators in atherosclerosis and CVD. How and where these proteins are modified and whether their carbohydrate alterations have functional impact on disease requires further study. The increased risks associated with non-O blood groups might be attributed to higher levels or functional modification of specific endothelial-derived GPs, specific platelet GPs, both sources, and/or GPs from additional cells and tissues although leukocytes are not likely primary sources as they lack the $\mathrm{ABO}$ enzyme [78].

The study of glycobiology in complex disease is in its relative infancy. Unbiased approaches are required to discover and identify the population of proteins and lipids that are modified by ABO (and other glycotransferases), in cells and tissues of specific relevance to atherothrombosis, so that we can define all potential mediators of specific aspects of risk and specific disease manifestations. Technological and bioinformatics advances, including mass-spectrometric approaches, are beginning to emerge which will permit such unbiased work. The tissue-specific expression and function of $\mathrm{ABO}$ and many known glycotransferases [79] suggest strongly that their actions and targets will be regulated at a cell- and tissue- specific levels coincident with roles in paracrine- and cell-specific events in atherothrombosis. A naïve impression might suggest that inhibition of $A B O$ glycotransferase functions, akin to the naturally occurring $\mathrm{ABO} O$ blood group, might provide a therapeutic strategy 
for lowering the risk of thrombosis and CVD. However, such a pharmacological approach would likely have untoward hematological and immunological consequences and/or nonspecific off target actions in cells and tissues not relevant to vascular diseases. Identification of the specific protein and lipid targets of $\mathrm{ABO}$ which mediate the functional effects in thrombosis, atherosclerosis and CVD is likely to provide greater opportunity for targeted therapeutic development and clinical translation. Whether targeting VWF carbohydrate modifications might provide clinically meaningful opportunities for treatment of thrombosis and $\mathrm{MI}$ is an open question.

There is much to be done to understand the role of $\mathrm{ABO}$ and glycobiology in CVD, and the next decade should see many advances in the basic biology, mechanistic actions, and diagnostic, prognostic, and therapeutic possibilities in humans. Thus, future studies to further define the association between $\mathrm{ABO}$ blood groups and cardiovascular events and risks, and to elucidate biochemical mechanisms responsible for these associations, are not only of basic scientific interest but also of translational clinical importance.

\section{Acknowledgments}

This work was supported by Award from the National Institutes of Health (NIH) including R01-HL-113147, R01HL-111694, R01-DK-090505, U01-HL108636, and K24HL107643 (to Muredach P. Reilly).

\section{References}

[1] I. I. El Hajj, J. G. Hashash, E. M. K. Baz, H. Abdul-Baki, and A. I. Sharara, "ABO blood group and gastric cancer: rekindling an old fire?" Southern Medical Journal, vol. 100, no. 7, pp. 726$727,2007$.

[2] T. Demir, A. Tezel, R. Orbak, A. Eltas, C. Kara, and F. Kavrut, "The effect of ABO blood types on periodontal status," European Journal of Dentistry, vol. 1, no. 3, pp. 139-143, 2007.

[3] M. A. Qureshi and R. Bhatti, "Frequency of abo blood groups among the diabetes mellitus type 2 patients," Journal of the College of Physicians and Surgeons Pakistan, vol. 13, no. 8, pp. 453-455, 2003.

[4] M. P. Reilly, M. Li, J. He et al., "Identification of ADAMTS7 as a novel locus for coronary atherosclerosis and association of $\mathrm{ABO}$ with myocardial infarction in the presence of coronary atherosclerosis: two genome-wide association studies," The Lancet, vol. 377, no. 9763, pp. 383-392, 2011.

[5] B. Woolf, "On estimating the relation between blood group and disease," Annals of Human Genetics, vol. 19, no. 4, pp. 251253, 1955.

[6] H. Jick, D. Slone, B. Westerholm et al., "Venous thromboembolic disease and $\mathrm{ABO}$ blood type. A cooperative study," The Lancet, vol. 1, no. 7594, pp. 539-542, 1969.

[7] P. P. Green, P. M. Mannucci, and E. Briet, "Carrier detection in hemophilia A: a cooperative international study. II. The efficacy of a universal discriminant," Blood, vol. 67, no. 6, pp. 1560-1567, 1986.

[8] J. H. Medalie, C. Levene, C. Papier et al., "Blood groups, myocardial infarction and angina pectoris among 10,000 adult males," New England Journal of Medicine, vol. 285, no. 24, pp. 1348-1353, 1971.
[9] T. R. Ketch, S. J. Turner, M. T. Sacrinty et al., "ABO blood types: influence on infarct size, procedural characteristics and prognosis," Thrombosis Research, vol. 123, no. 2, pp. 200-205, 2008.

[10] J. Erikssen, E. Thaulow, and H. Stormorken, "ABO blood groups and coronary heart disease (CHD). A study in subjects with severe and latent CHD," Thrombosis and Haemostasis, vol. 43, no. 2, pp. 137-140, 1980.

[11] U. E. Nydegger, W. A. Wuillemin, F. Julmy, B. J. Meyer, and T. P. Carrel, "Association of ABO histo-blood group B allele with myocardial infarction," European Journal of Immunogenetics, vol. 30, no. 3, pp. 201-206, 2003.

[12] D. Platt, W. Muhlberg, L. Kiehl, and R. Schmitt-Ruth, "ABO blood group system, age, sex, risk factors and cardiac infarction," Archives of Gerontology and Geriatrics, vol. 4, no. 3, pp. 241-249, 1985.

[13] I. Sari, O. Ozer, V. Davutoglu, S. Gorgulu, M. Eren, and M. Aksoy, "ABO blood group distribution and major cardiovascular risk factors in patients with acute myocardial infarction," Blood Coagulation and Fibrinolysis, vol. 19, no. 3, pp. 231-234, 2008.

[14] O. Wu, N. Bayoumi, M. A. Vickers, and P. Clark, "ABO $(\mathrm{H})$ blood groups and vascular disease: a systematic review and meta-analysis," Journal of Thrombosis and Haemostasis, vol. 6, no. 1, pp. 62-69, 2008.

[15] R. Oriol, R. Mollicone, P. Coullin, A. M. Dalix, and J. J. Candelier, "Genetic regulation of the expression of $\mathrm{ABH}$ and Lewis antigens in tissues," APMIS, Supplement, vol. 100, no. 27, pp. 28-38, 1992.

[16] E. Hosoi, "Biological and clinicel aspects of $\mathrm{ABO}$ blood group system," Journal of Medical Investigation, vol. 55, no. 3-4, pp. 174-182, 2008.

[17] P. V. Jenkins and J. S. O’Donnell, “ABO blood group determines plasma von Willebrand factor levels: a biologic function after all?" Transfusion, vol. 46, no. 10, pp. 1836-1844, 2006.

[18] J. R. Storry and M. L. Olsson, "The ABO blood group system revisited: a review and update," Immunohematology, vol. 25, no. 2, pp. 48-59, 2009.

[19] J. B. Lowe, "The blood group-specific human glycosyltransferases," Bailliere's Clinical Haematology, vol. 6, no. 2, pp. 465492, 1993.

[20] T. Zeller, S. Blankenberg, and P. Diemert, "Genomewide association studies in cardiovascular disease-an update 2011," Clinical Chemistry, vol. 58, no. 1, pp. 92-103, 2012.

[21] L. Qi, M. C. Cornelis, P. Kraft et al., "Genetic variants in ABO blood group region, plasma soluble E-selectin levels and risk of type 2 diabetes," Human Molecular Genetics, vol. 19, no. 9, Article ID ddq057, pp. 1856-1862, 2010.

[22] A. D. Paterson, M. F. Lopes-Virella, D. Waggott et al., "Genome-wide association identifies the ABO blood group as a major locus associated with serum levels of soluble Eselectin," Arteriosclerosis, Thrombosis, and Vascular Biology, vol. 29, no. 11, pp. 1958-1967, 2009.

[23] J. A. Heit, S. M. Armasu, Y. W. Asmann et al., "A genomewide association study of venous thromboembolism identifies risk variants in chromosomes 1q24.2 and 9q," Journal of Thrombosis and Haemostasis, vol. 10, no. 8, pp. 1521-1531, 2012.

[24] C. M. Chung, R. Y. Wang, J. W. Chen et al., "A genomewide association study identifies new loci for ACE activity: potential implications for response to ACE inhibitor," Pharmacogenomics Journal, vol. 10, no. 6, pp. 537-544, 2010.

[25] M. Barbalic, J. Dupuis, A. Dehghan et al., "Large-scale genomic studies reveal central role of $\mathrm{ABO}$ in sP-selectin and 
sICAM-1 levels," Human Molecular Genetics, vol. 19, no. 9, Article ID ddq061, pp. 1863-1872, 2010.

[26] T. M. Teslovich, K. Musunuru, A. V. Smith et al., "Biological, clinical and population relevance of 95 loci for blood lipids," Nature, vol. 466, no. 7307, pp. 707-713, 2010.

[27] S. Kiechl, G. Pare, M. Barbalic et al., "Association of variation at the ABO locus with circulating levels of soluble intercellular adhesion molecule-1, soluble P-selectin, and soluble Eselectin: a meta-analysis," Circulation, vol. 4, no. 6, pp. 681686, 2011.

[28] D. Zabaneh, T. R. Gaunt, M. Kumari et al., "Genetic variants associated with von Willebrand factor levels in healthy men and women identified using the humanCVD beadchip," Annals of Human Genetics, vol. 75, no. 4, pp. 456-467, 2011.

[29] K. L. Wiggins, N. L. Smith, N. L. Glazer et al., "ABO genotype and risk of thrombotic events and hemorrhagic stroke," Journal of Thrombosis and Haemostasis, vol. 7, no. 2, pp. 263269, 2009.

[30] G. Paré, P. M. Ridker, L. Rose et al., "Genome-wide association analysis of soluble ICAM-1 concentration reveals novel associations at the NFKBIK, PNPLA3, RELA, and SH2B3 loci," PLoS Genetics, vol. 7, no. 4, Article ID e1001374, 2011.

[31] G. Paré, D. I. Chasman, M. Kellogg et al., "Novel association of ABO histo-blood group antigen with soluble ICAM-1: results of a genome-wide association study of 6,578 women," PLoS Genetics, vol. 4, no. 7, Article ID e1000118, 2008.

[32] D. A. Tregouet, S. Heath, N. Saut et al., "Common susceptibility alleles are unlikely to contribute as strongly as the FV and ABO loci to VTE risk: results from aGWAS approach," Blood, vol. 113, no. 21, pp. 5298-5303, 2009.

[33] M. Campos, W. Sun, F. Yu et al., "Genetic determinants of plasma von Willebrand factor antigen levels: a target gene SNP and haplotype analysis of ARIC cohort," Blood, vol. 117, no. 19, pp. 5224-5230, 2011.

[34] N. L. Smith, M. H. Chen, A. Dehghan et al., "Novel associations of multiple genetic loci with plasma levels of factor VII, factor VIII, and von Willebrand factor: the CHARGE (Cohorts for Heart and Aging Research in Genome Epidemiology) Consortium," Circulation, vol. 121, no. 12, pp. 1382-1392, 2010.

[35] D. Teupser, R. Baber, U. Ceglarek et al., "Genetic regulation of serum phytosterol levels and risk of coronary artery disease," Circulation, vol. 3, no. 4, pp. 331-339, 2010.

[36] J. C. Gill, J. Endres-Brooks, and P. J. Bauer, "The effect of ABO blood group on the diagnosis of von Willebrand disease," Blood, vol. 69, no. 6, pp. 1691-1695, 1987.

[37] D. R. Rios, A. P. Fernandes, R. C. Figueiredo et al., "Relationship between $\mathrm{ABO}$ blood groups and von Willebrand factor, ADAMTS13 and factor VIII in patients undergoing hemodialysis," Journal of Thrombosis and Thrombolysis, vol. 33, no. 4, pp. 416-421, 2012.

[38] J. C. Souto, L. Almasy, J. M. Soria et al., "Genome-wide linkage analysis of von Willebrand factor plasma levels: results from the GAIT project," Thrombosis and Haemostasis, vol. 89, no. 3, pp. 468-474, 2003.

[39] V. Terraube, J. S. O’Donnell, and P. V. Jenkins, "Factor VIII and von Willebrand factor interaction: biological, clinical and therapeutic importance," Haemophilia, vol. 16, no. 1, pp. 3-13, 2010.

[40] R. A. Kraaijenhagen, P. S. In 'T Anker, M. M. W. Koopman et al., "High plasma concentration of factor VIIIc is a major risk factor for venous thromboembolism," Thrombosis and Haemostasis, vol. 83, no. 1, pp. 5-9, 2000.
[41] T. Koster, A. D. Blann, E. Briet, J. P. Vandenbroucke, and F. R. Rosendaal, "Role of clotting factor VIII in effect of von Willebrand factor on occurrence of deep-vein thrombosis," The Lancet, vol. 345, no. 8943, pp. 152-155, 1995.

[42] F. I. Yamamoto, P. D. McNeill, and S. I. Hakomori, "Human histo-blood group A2 transferase coded by A2 allele, one of the A subtypes, is characterized by a single base deletion in the coding sequence, which results in an additional domain at the carboxyl terminal," Biochemical and Biophysical Research Communications, vol. 187, no. 1, pp. 366-374, 1992.

[43] V. M. Morelli, M. C. H. de Visser, N. H. van Tilburg et al., "ABO blood group genotypes, plasma von Willebrand factor levels and loading of von Willebrand factor with A and B antigens," Thrombosis and Haemostasis, vol. 97, no. 4, pp. 534$541,2007$.

[44] S. le Cessie, J. Debeij, F. R. Rosendaal, S. C. Cannegieter, and J. P. Vandenbroucke, "Quantification of bias in direct effects estimates due to different types of measurement error in the mediator," Epidemiology, vol. 23, no. 4, pp. 551-560, 2012.

[45] V. M. Morelli, M. C. H. De Visser, H. L. Vos, R. M. Bertina, and F. R. Rosendaal, "ABO blood group genotypes and the risk of venous thrombosis: effect of factor V Leiden," Journal of Thrombosis and Haemostasis, vol. 3, no. 1, pp. 183-185, 2005.

[46] T. W. Meade, J. A. Cooper, Y. Stirling, D. J. Howarth, V. Ruddock, and G. J. Miller, "Factor VIII, ABO blood group and the incidence of ischaemic heart disease," British Journal of Haematology, vol. 88, no. 3, pp. 601-607, 1994.

[47] R. J. Garrison, R. J. Havlik, R. B. Harris, M. Feinleib, W. B. Kannel, and S. J. Padgett, "ABO blood group and cardiovacular disease the Framingham study," Atherosclerosis, vol. 25, no. 23, pp. 311-318, 1976.

[48] N. Saha, C. C. S. Toh, and M. B. Ghosh, "Genetic association in myocardial infarction. Ethnicity; $\mathrm{ABO}, \mathrm{Rh}, \mathrm{Le}(\mathrm{a}), \mathrm{Xg}(\mathrm{a})$ blood groups; G6PD deficiency; and abnormal hemoglobins," Journal of Medical Genetics, vol. 10, no. 4, pp. 340-345, 1973.

[49] B. Bronte-Stewart, M. C. Botha, and L. H. Krut, "ABO blood groups in relation to ischaemic heart disease," British Medical Journal, vol. 1, no. 5293, pp. 1646-1650, 1962.

[50] M. He, B. Wolpin, K. Rexrode et al., "ABO blood group and risk of coronary heart disease in two prospective cohort studies," Arteriosclerosis, Thrombosis, and Vascular Biology, vol. 32, no. 9, pp. 2314-2320, 2012.

[51] B. R. Curtis, J. T. Edwards, M. J. Hessner, J. P. Klein, and R. H. Aster, "Blood group A and B antigens are strongly expressed on platelets of some individuals," Blood, vol. 96, no. 4, pp. 1574-1581, 2000.

[52] D. Stockelberg, M. Hou, L. Rydberg, J. Kutti, and H. Wadenvik, "Evidence for an expression of blood group A antigen on platelet glycoproteins IV and V," Transfusion Medicine, vol. 6, no. 3, pp. 243-248, 1996.

[53] M. Hou, D. Stockelberg, L. Rydberg, J. Kutti, and H. Wadenvik, "Blood group A antigen expression in platelets is prominently associated with glycoprotein Ib and IIb. Evidence for an A1/A2 difference," Transfusion Medicine, vol. 6, no. 1, pp. 51-59, 1996.

[54] K. Ogasawara, J. Ueki, M. Takenaka, and K. Furihata, "Study on the expression of ABH antigens on platelets," Blood, vol. 82, no. 3, pp. 993-999, 1993.

[55] N. Gaudreault, N. Kumar, J. M. Posada et al., "ApoE suppresses atherosclerosis by reducing lipid accumulation in circulating monocytes and the expression of inflammatory molecules on monocytes and vascular endothelium," Arteriosclerosis, Thrombosis, and Vascular Biology, vol. 32, no. 2, pp. 264-272, 2012. 
[56] T. Takeshi, N. Keisuke, I. Takaaki, Y. Makoto, and N. Tatsuji, "Involvement of adhesion molecule in in vitro plaque-like formation of macrophages stimulated with Aggregatibacter actinomycetemcomitans lipopolysaccharide," Journal of Periodontal Research, vol. 45, no. 4, pp. 550-556, 2010.

[57] W. Luo, H. Wang, M. K. Ohman et al., "P-selectin glycoprotein ligand-1 deficiency leads to cytokine resistance and protection against atherosclerosis in apolipoprotein E deficient mice," Atherosclerosis, vol. 220, no. 1, pp. 110-117, 2012.

[58] J. Kisucka, A. K. Chauhan, B. Q. Zhao et al., "Elevated levels of soluble P-selectin in mice alter blood-brain barrier function, exacerbate stroke, and promote atherosclerosis," Blood, vol. 113, no. 23, pp. 6015-6022, 2009.

[59] T. P. Johnston, "Poloxamer 407 increases soluble adhesion molecules, ICAM-1, VCAM-1 and E-selectin, in C57BL/6 mice," Journal of Pharmacy and Pharmacology, vol. 61, no. 12, pp. 1681-1688, 2009.

[60] P. M. Ridker, C. H. Hennekens, B. Roitman-Johnson, M. J. Stampfer, and J. Allen, "Plasma concentration of soluble intercellular adhesion molecule 1 and risks of future myocardial infarction in apparently healthy men," The Lancet, vol. 351, no. 9096, pp. 88-92, 1998.

[61] S. J. Hwang, C. M. Ballantyne, A. R. Sharrett et al., "Circulating adhesion molecules VCAM-1, ICAM-1, and E-selectin in carotid atherosclerosis and incident coronary heart disease cases: the Atherosclerosis Risk In Communities (ARIC) study," Circulation, vol. 96, no. 12, pp. 4219-4225, 1997.

[62] M. F. Oliver, H. Geizerova, R. A. Cumming, and J. A. Heady, "Serum-cholesterol and ABO and rhesus blood-groups," The Lancet, vol. 2, no. 7621, pp. 605-606, 1969.

[63] M. J. Langman, P. C. Elwood, J. Foote, and D. R. Ryrie, "ABO and Lewis blood-groups and serum-cholesterol," The Lancet, vol. 2, no. 7621, pp. 607-609, 1969.

[64] C. Carpeggiani, M. Coceani, P. Landi, C. Michelassi, and A. L'Abbate, "ABO blood group alleles: a risk factor for coronary artery disease. An angiographic study," Atherosclerosis, vol. 211, no. 2, pp. 461-466, 2010.

[65] E. Contiero, G. E. Chinello, and M. Folin, "Serum lipids and lipoproteins associations with ABO blood groups," Anthropologischer Anzeiger, vol. 52, no. 3, pp. 221-230, 1994.

[66] D. I. Chasman, G. Paré, S. Mora et al., "Forty-three loci associated with plasma lipoprotein size, concentration, and cholesterol content in genome-wide analysis," PLoS Genetics, vol. 5, no. 11, Article ID e1000730, 2009.

[67] A. K. Chauhan, J. Kisucka, C. B. Lamb, W. Bergmeier, and D. D. Wagner, "Von Willebrand factor and factor VIII are independently required to form stable occlusive thrombi in injured veins," Blood, vol. 109, no. 6, pp. 2424-2429, 2007.

[68] I. Tirado, J. Mateo, J. M. Soria et al., "The ABO blood group genotype and factor VIII levels as independent risk factors for venous thromboembolism," Thrombosis and Haemostasis, vol. 93, no. 3, pp. 468-474, 2005.

[69] P. M. Mannucci, C. Capoferri, and M. T. Canciani, "Plasma levels of von Willebrand factor regulate ADAMTS-13, its major cleaving protease," British Journal of Haematology, vol. 126, no. 2, pp. 213-218, 2004.

[70] D. J. Bowen, "An influence of ABO blood group on the rate of proteolysis of von Willebrand factor by ADAMTS13," Journal of Thrombosis and Haemostasis, vol. 1, no. 1, pp. 33-40, 2003.

[71] I. Badirou, M. Kurdi, J. Rayes et al., "von Willebrand factor clearance does not involve proteolysis by ADAMTS-13," Journal of Thrombosis and Haemostasis, vol. 8, no. 10, pp. 23382340, 2010.
[72] R. T. McGrath, E. McRae, O. P. Smith, and J. S. O’Donnell, "Platelet von Willebrand factor-structure, function and biological importance," British Journal of Haematology, vol. 148, no. 6, pp. 834-843, 2010.

[73] S. C. Barbaux, S. Blankenberg, H. J. Rupprecht et al., "Association between P-selectin gene polymorphisms and soluble P-selectin levels and their relation to coronary artery disease," Arteriosclerosis, Thrombosis, and Vascular Biology, vol. 21, no. 10, pp. 1668-1673, 2001.

[74] L. L. W. Cooling, K. Kelly, J. Barton, D. Hwang, T. A. W. Koerner, and J. D. Olson, "Determinants of ABH expression on human blood platelets," Blood, vol. 105, no. 8, pp. 33563364, 2005.

[75] Y. Cadroy, K. S. Sakariassen, J. P. Charlet, C. Thalamas, B. Boneu, and P. Sie, "Role of 4 platelet membrane glycoprotein polymorphisms on experimental arterial thrombus formation in men," Blood, vol. 98, no. 10, pp. 3159-3161, 2001.

[76] C. Meisel, J. A. López, and K. Stangl, "Role of platelet glycoprotein polymorphisms in cardiovascular diseases," NaunynSchmiedeberg's Archives of Pharmacology, vol. 369, no. 1, pp. 38-54, 2004.

[77] A. M. Carter, M. W. Mansfield, and P. J. Grant, "Polymorphisms of platelet glycoproteins in relation to macrovascular disease in type 2 diabetes mellitus," Diabetic Medicine, vol. 15, no. 4, pp. 315-319, 1998.

[78] R. A. Dunstan, "Status of major red cell blood group antigens on neutrophils, lymphocytes and monocytes," British Journal of Haematology, vol. 62, no. 2, pp. 301-309, 1986.

[79] A. Varki, "Evolutionary forces shaping the Golgi glycosylation machinery: why cell surface glycans are universal to living cells," Cold Spring Harbor Perspectives in Biology, vol. 3, no. 6, p. a005462, 2011. 


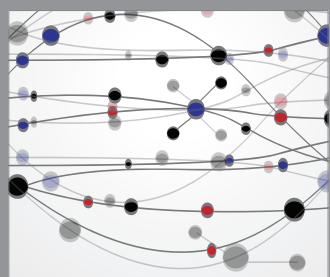

The Scientific World Journal
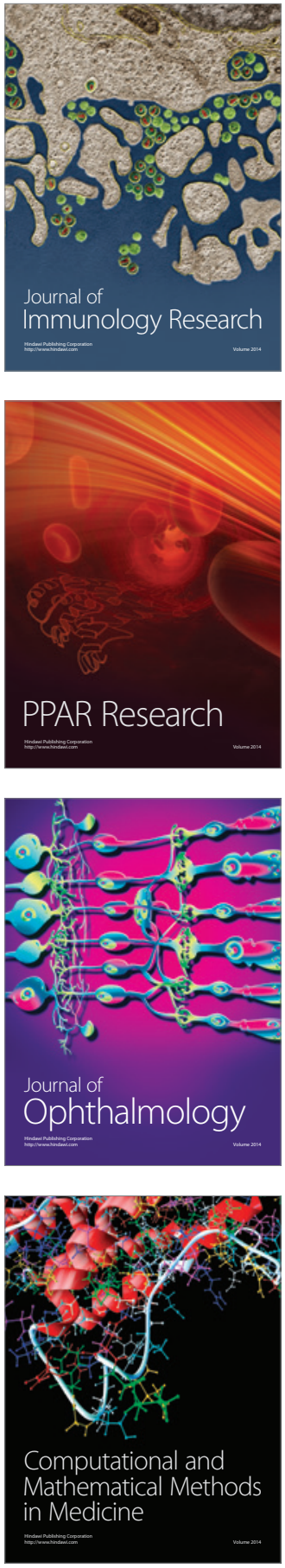

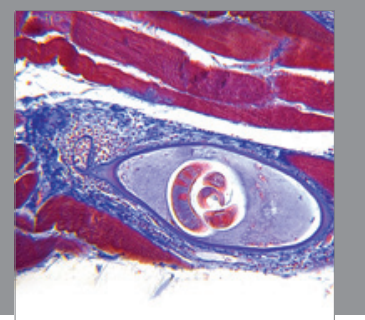

Gastroenterology

Research and Practice
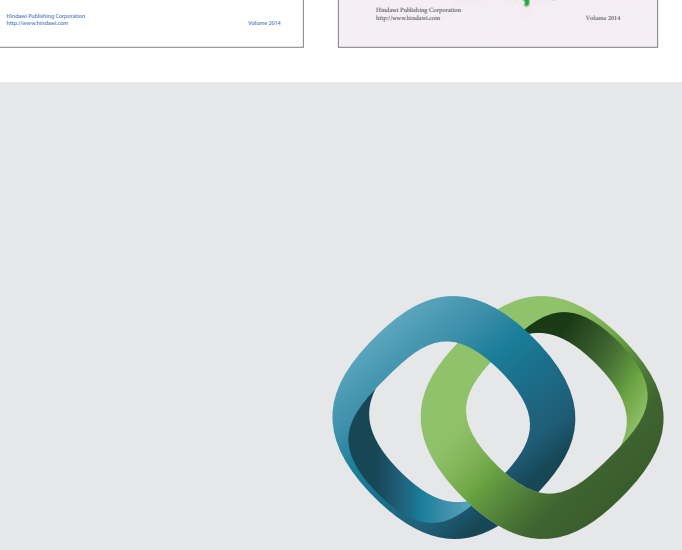

\section{Hindawi}

Submit your manuscripts at

http://www.hindawi.com
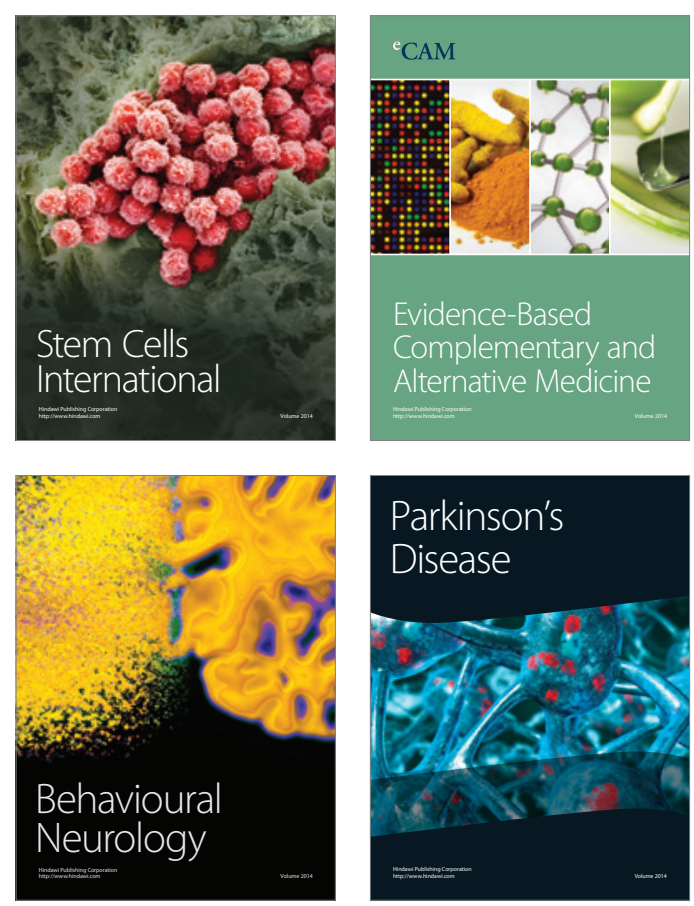

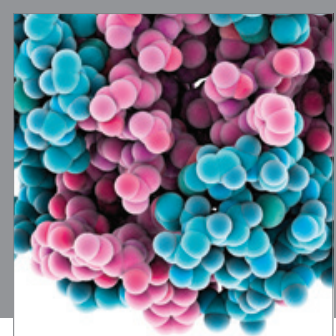

Journal of
Diabetes Research

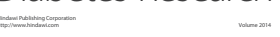

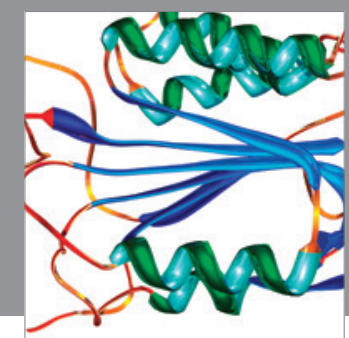

Disease Markers
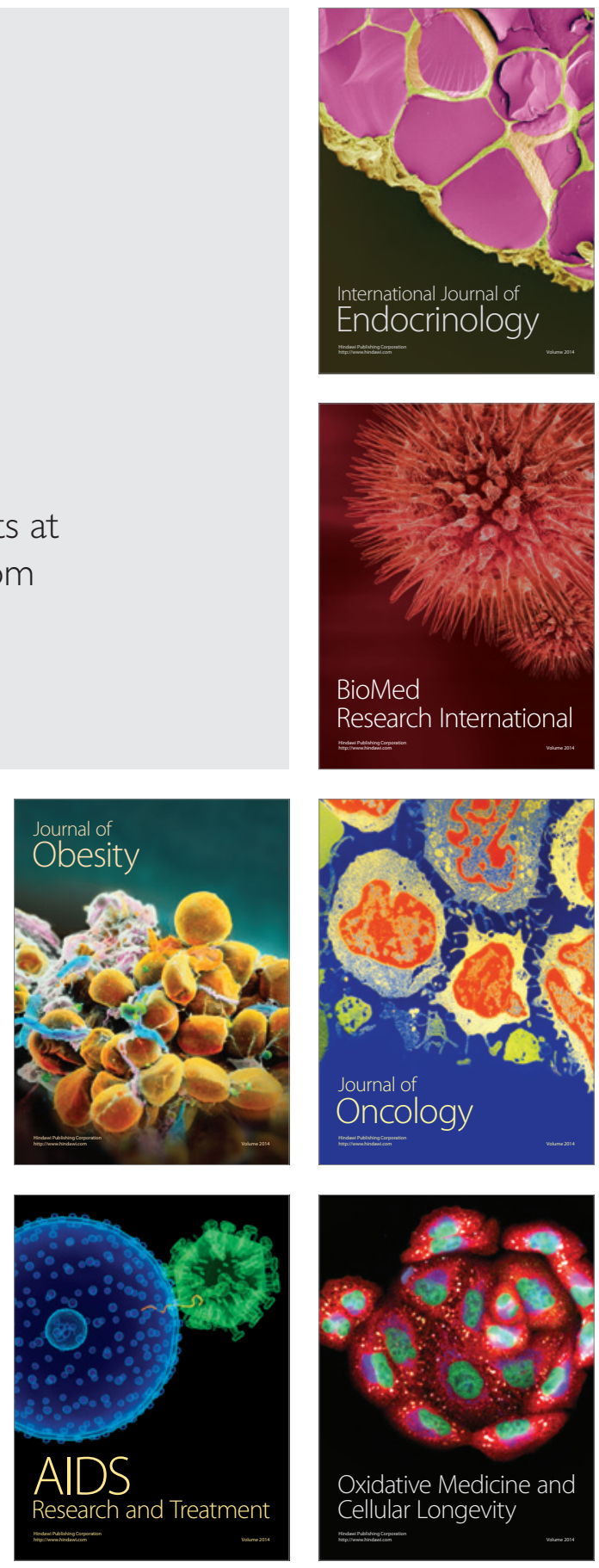